\title{
Type 2 diabetes, thiazolidinediones, and cardiovascular risk
}

Clare Taylor and FD Richard Hobbs

\begin{abstract}
Type 2 diabetes is a common disorder with an increased risk of macrovascular complications. Achieving adequate glycaemic control is an important aim of therapy. Thiazolidinediones, or glitazones, have been used for the treatment of diabetes for a decade. Rosiglitazone and pioglitazone are currently available, however recent concerns around cardiovascular safety have led to restrictions on their use. Initial trials showed treatments with glitazones improved glycaemic control, however long-term outcomes such as cardiovascular events were not measured. Evidence from more recent trials suggests rosiglitazone is associated with an increased risk of cardiovascular events and both glitazones are associated with higher rates of heart failure. This article discusses the evidence behind these concerns and the most recent guidance on use of thiazolidinediones in clinical practice.

Keywords

cardiovascular risk; glitazones; heart failure; thiazolidinediones; type 2 diabetes.
\end{abstract}

\section{BACKGROUND}

Type 2 diabetes is a disorder of insulin resistance and $\beta$ cell failure, causing chronic hyperglycaemia. ${ }^{1}$ There are over 1.5 million people in the UK and 194 million people worldwide with known diabetes, and many more may be undiagnosed. The incidence is rising rapidly, and an estimated 330 million of the world population will be affected by $2025 .^{2}$

Patients with type 2 diabetes are at increased risk of vascular disease: macrovascular complications, such as myocardial infarction, stroke, and peripheral vascular disease, are common causes of morbidity and premature mortality; ${ }^{3}$ microvascular disease, primarily affecting the nerves, eyes, and kidneys, can lead to neuropathy, blindness, and renal failure. Microvascular complications are reduced with adequate blood glucose control, but this has not been shown, in isolation, to be the case for macrovascular complications. ${ }^{4}$

The thiazolidinediones (also known as glitazones), or peroxisome-proliferator-activated receptors agonists, are one of the main classes of oral hypoglycaemics and were introduced a decade ago. They improve glycaemic control by increasing insulin sensitivity in fat, liver, and muscle, and may have a role in $\beta$ cell protection. ${ }^{5}$ Troglitazone, the first drug in this class introduced in 1997 in the UK, was withdrawn following cases of hepatotoxicity. ${ }^{6}$ Two glitazones, rosiglitazone and pioglitazone, are currently available as single agents or in combination with metformin or sulphonylureas. Initial trials prior to licensing of glitazones concentrated on surrogate endpoints such as glycaemic control rather than clinical outcomes, and especially cardiovascular disease. ${ }^{7}$ However, cardiovascular events are a late complication of diabetes, and some trials were not long enough to identify any difference in cardiovascular outcomes between treatment groups. Despite this, there have been recent concerns that glitazones may be associated with an increased cardiovascular risk, and this article reports recent evidence behind the controversy and the current guidance regarding their use.

\section{ROSIGLITAZONE: ADOPT A DREAM?}

The potential benefits of rosiglitazone in terms of reduced progression to type 2 diabetes and prolonged glycaemic control emerged recently. The DREAM (Diabetes REduction Assessment with ramipril and rosiglitazone Medication) trial published in late 2006 involved 5269 patients with impaired glucose tolerance or impaired fasting glucose, with no history of cardiovascular disorders, in 21 countries, randomly assigned to rosiglitazone $8 \mathrm{mg}$ daily or placebo and followed up for a median of

C Taylor, MA, DCH, MRCP, academic registrar; FDR Hobbs, FRCP, FRCGP, FESC, FMedSci, professor and head of department, Primary Care Clinical Services, University of Birmingham, Birmingham.

Address for correspondence Dr Clare Taylor, Primary Care Clinical Sciences, University of Birmingham, Edgbaston, Birmingham B15 2TT. E-mail: c.j.taylor.1@bham.ac.uk

Submitted: 16 July 3008; Editor's response: 27 October 2008; final acceptance: 4 December 2008.

(C)British Journal of General Practice

This article was originally online first on 11 June 2009. Cite this article as: Br J Gen Pract 2009; 59: 520-524. Advance online publication. DOI: 10.3399/bjgp09X453440 
3 years; $10.6 \%$ of patients in the rosiglitazone group compared with $25.0 \%$ in the placebo group developed type 2 diabetes (hazard ratio $[\mathrm{HR}]=0.38$, $95 \%$ confidence interval $[\mathrm{Cl}]=0.33$ to 0.44 , $P<0.001)$. Furthermore, $50.5 \%$ of those receiving rosiglitazone became normoglycaemic (fasting blood glucose $<6.1 \mathrm{mmol} / \mathrm{l}$ ) compared with $30.3 \%$ in the placebo arm $(\mathrm{HR}=1.71,95 \% \mathrm{Cl}=1.57$ to 1.87 , $P<0.001)$. Fourteen patients in the rosiglitazone group developed heart failure, compared with only two patients in the placebo group $(\mathrm{HR}=7.03,95 \%$ $\mathrm{Cl}=1.60$ to $30.9, P=0.01){ }^{8}$

Later that year, the ADOPT (A Diabetes Outcome Progression Trial) study group reported results of a randomised controlled trial comparing the efficacy of monotherapy with oral hypoglycaemics in 4360 recently diagnosed patients with type 2 diabetes. Patients were randomised to metformin, glyburide, or rosiglitazone monotherapy, with follow-up for a median time of 4 years. Time to failure of monotherapy (defined by fasting plasma glucose of $\geq 10 \mathrm{mmol} / \mathrm{l}$ ) was the primary outcome measure. Monotherapy failed at a rate of 4.3 per 100 patientyears in patients receiving metformin, 7.5 per 100 patient-years for glyburide, and 2.9 per 100 patientyears for rosiglitazone. The risk of treatment failure was reduced by $32 \%(95 \% \mathrm{Cl}=15$ to $45 \%, P<0.001)$ with rosiglitazone compared with metformin, and $63 \%(95 \% \mathrm{Cl}=55$ to $10 \%, P<0.001)$ with rosiglitazone compared with glyburide. However, significantly more oedema requiring loop diuretics was seen in patients receiving rosiglitazone $(14.1 \%$ versus $7.2 \%$ with metformin and $8.5 \%$ with glyburide, $P<0.01$ ), and heart failure was less common in patients receiving glyburide compared with rosiglitazone $(0.6 \%$ versus $1.5 \%, P<0.05)$. However, diarrhoea and abdominal discomfort were less common in those taking rosiglitazone compared with metformin $(23.0 \%$ versus $38.3 \%, P<0.001)$, and hypoglycaemia was less common than in those taking glyburide (9.8\% versus $38.7 \%, P<0.001)$. The study also reported (at proof stage) an unexpected statistically significant increase in fracture rates in women in the rosiglitazone group compared with the metformin or glyburide groups $(9.30 \%$ versus $5.08 \%$ and $3.47 \%$ respectively, $P<0.01){ }^{9}$

\section{ROSIGLITAZONE AND RISK OF CARDIOVASCULAR EVENTS}

Following concerns regarding lack of evidence on cardiovascular outcomes in patients with type 2 diabetes taking glitazones, Nissen and Wolski conducted a meta-analysis to look at the effect of rosiglitazone on the risk of cardiovascular events in May $2007 . .^{10}$ The meta-analysis included the published data from 42 randomised controlled trials involving

\section{How this fits in}

Thiazolidinediones are an important class of agent for achieving and

maintaining adequate glycaemic control in type 2 diabetes. They should not be used in patients with existing heart failure, and should be used with caution in those with known vascular disease or at increased risk of fracture. Current evidence suggests pioglitazone is the first-choice glitazone.

15560 patients with a treatment regime including rosiglitazone, and 12283 patients receiving control (placebo, metformin, sulphonylurea, or insulin) for more than 24 weeks, comparing data on myocardial infarction or cardiovascular death. There was a statistically significant increase in myocardial infarction in those receiving rosiglitazone compared with controls. Eighty-six patients in the rosiglitazone group had a myocardial infarction, compared with 72 patients in the control group (odds ratio $[\mathrm{OR}]=1.43 ; 95 \% \mathrm{Cl}=$ 1.03 to $1.98, P=0.03$ ). There were 39 deaths from cardiovascular disease in the rosiglitazone group and 22 deaths in the control group, but the difference between groups was not statistically significant $(\mathrm{OR}=$ $1.64 ; 95 \% \mathrm{Cl}=0.98$ to $2.74, P=0.06) .{ }^{10}$

The meta-analysis provoked huge controversy since it reported data available to the drug licensing authority in the US, the Food and Drug Administration (FDA), with the implication that the FDA had failed to report the risks. The meta-analysis was also criticised for potential methodological flaws as some of the trials included in the analysis were small and there were no standard outcome measures applied across the studies. The numbers of myocardial infarction and cardiovascular deaths were also small, and patientlevel data were not available, meaning any time-toevent analysis was not possible. ${ }^{11}$

A Cochrane review published shortly after this meta-analysis looked at 18 randomised trials including 3888 patients receiving rosiglitazone for a median of 26 weeks, and concluded there was no difference in overall mortality, morbidity, or adverse events in the rosiglitazone groups compared to other antidiabetic medications. There was, however, a significantly increased risk of oedema in the rosiglitazone groups $(\mathrm{OR}=2.27 ; 95 \% \mathrm{Cl}=1.83$ to $2.81, P<0.001)$. The ADOPT study contributed largely to the number of patients in this review, and many of the other trials included were small studies of short duration. ${ }^{12}$

The controversy further prompted the RECORD (Rosiglitazone Evaluated for Cardiac Outcomes and Regulation of Glycaemia in Diabetes) study group to publish an interim analysis of their ongoing randomised controlled trial involving 4447 type 2 diabetes patients with a glycosylated haemoglobin 
(HbA1c) between 7.0 and $9.0 \%$, on maximum doses of metformin or a sulphonylurea. ${ }^{13}$ Patients received either rosiglitazone in addition to current treatment or a combination of both metformin and a sulphonylurea (control). The results showed no statistically significant difference between the rosiglitazone and control groups in terms of admissions to hospitalisation or deaths due to cardiovascular disease $(\mathrm{HR}=1.08 ; 95 \% \mathrm{Cl}=0.89$ to 1.31, $P=0.43$ ). There was, however, an increased risk of heart failure in patients receiving rosiglitazone ( $\mathrm{HR}=2.24 ; 95 \% \mathrm{Cl}=1.27$ to $3.97, P=0.006)$. The authors point out that, as an interim report, the short duration of follow-up limited the power of the study to detect any differences between the rosiglitazone and control groups, suggesting results should be viewed as inconclusive at this stage in the study..$^{13}$

A subsequent meta-analysis in September 2007 included DREAM, ADOPT, and RECORD interim results, and a smaller study looking at the effects of rosiglitazone in patients with heart failure. ${ }^{14} \mathrm{~A}$ total of 14291 patients, 6421 in the rosiglitazone group and 7870 in the control group, with at least 1 year followup, were compared for cardiovascular outcomes. The risk of myocardial infarction was significantly higher in the group receiving rosiglitazone compared with control (risk ratio $[\mathrm{RR}]=1.42 ; 95 \% \mathrm{Cl}=1.06$ to 1.91 , $P=0.02$ ); however, there was no increased risk in cardiovascular mortality $(\mathrm{RR}=0.90 ; 95 \% \mathrm{Cl}=0.63$ to $1.26, P=0.53)$. The meta-analysis also found a higher rate of heart failure in the rosiglitazone group than control group (RR $=2.09 ; 95 \% \mathrm{Cl}=1.52$ to 2.88 , $P<0.01){ }^{15}$

\section{PIOGLITAZONE - PARADOXICALLY CARDIOPROTECTIVE?}

Pioglitazone has not attracted the same degree of controversy as rosiglitazone with regard to risk of myocardial infarction. In fact there is an increasing amount of evidence to support a modest cardioprotective role in terms of ischaemic events for pioglitazone in patients with type 2 diabetes.

A large retrospective cohort involving 29911 patients comparing hospitalisation for acute myocardial infarction in patients with type 2 diabetes treated with pioglitazone or rosiglitazone found a $22 \%$ relative risk reduction in the pioglitazone group ( $\mathrm{HR}=0.78 ; 95 \% \mathrm{Cl}=0.63$ to 0.96$).{ }^{16}$ However, if rosiglitazone increases the risk of myocardial infarction, this may represent a neutral rather than protective effect of pioglitazone.

The PROactive (PROspective pioglitAzone Clinical Trial In macroVascular Events) study, a randomised controlled trial, investigated secondary prevention of macrovascular complications in 5238 patients with type 2 diabetes and a history of macrovascular disease (myocardial infarction, stroke, acute coronary syndrome, peripheral arterial disease, or coronary artery bypass graft). ${ }^{17}$ Patients were randomised to receive pioglitazone or placebo alongside their usual medications. The primary endpoint in the analysis, which included all-cause mortality, acute coronary syndrome, non-fatal myocardial infarction, coronary revascularisation, stroke, and surgical intervention for peripheral vascular disease, failed to show a statistically significant difference between the two groups ( $\mathrm{HR}=$ $0.90 ; 95 \% \mathrm{Cl}=0.80$ to $1.02, P=0.095)$. However, the secondary endpoint of all-cause mortality, non-fatal myocardial infarction, and stroke showed a significant difference in favour of pioglitazone $(\mathrm{HR}=$ $0.84 ; 95 \% \mathrm{Cl}=0.72$ to $0.98, P=0.027$ ). Overall rates of heart failure were significantly higher in the pioglitazone group ( $11 \%$ versus $8 \%, P<0.001)$, although death from heart failure was not different between the two groups ( $1 \%$ versus $1 \%, P=0.634$ ).

In subgroup analysis of the pioglitazone arm of the PROactive trial, patients with a history of previous myocardial infarction had a $28 \%$ risk reduction in recurrence of fatal or non-fatal myocardial infarction $(\mathrm{HR}=0.72 ; 95 \% \mathrm{Cl}=0.52$ to $0.99, P=0.045) .{ }^{18}$ Those PROactive patients with a previous history of stroke had a significantly reduced risk of further fatal or non-fatal stroke $(\mathrm{HR}=0.53 ; 95 \% \mathrm{Cl}=0.34$ to 0.85 , $P=0.009) .{ }^{19}$

A recent meta-analysis involving 19 randomised controlled trials with a total of 16390 patients used patient-level data to compare cardiovascular outcomes between groups of patients receiving pioglitazone or control for between 4 months and 3.5 years. Primary outcomes including myocardial infarction, stroke, or death were all reduced significantly in the pioglitazone group compared with the control group ( $\mathrm{HR}=0.82 ; 95 \% \mathrm{Cl}=0.72$ to 0.94 , $P=0.005)$. There was an increased risk of heart failure in patients receiving pioglitazone compared with controls $(\mathrm{HR}=1.41 ; 95 \% \mathrm{Cl}=1.14$ to $1.76, P=$ 0.002 ), but death from heart failure was not significantly higher $(\mathrm{HR}=1.11 ; 95 \% \mathrm{Cl}=0.96$ to 1.29, $P=0.17) .{ }^{20}$

The mechanisms underlying this possible protective effect were explored in the PERISCOPE (Pioglitazone Effect on Regression of Intravascular Sonographic Coronary Obstruction Prospective Evaluation) study, a randomised controlled trial in 543 patients with coronary artery disease and type 2 diabetes, randomised to receive glimepiride (a sulphonylurea) or pioglitazone. Atheroma volume before treatment and at 18 months, assessed using intravascular ultrasound, showed less progression in the pioglitazone group - a decrease in mean percentage atheroma volume of $0.16 \%(95 \% \mathrm{Cl}=$ 
0.57 to $0.25 \%, P=0.002$ ) with pioglitazone, compared with an increase of $0.73 \%(95 \% \mathrm{Cl}=0.33$ to $1.12 \%, P=0.002$ ) with glimepiride, a statistically significant difference..$^{21}$ High-density lipoprotein was higher and triglyceride lower in patients receiving pioglitazone. A similar slowing of disease progression was seen in a randomised trial looking at carotid intima-media thickness, thought to be a reliable intermediate marker for coronary atherosclerosis, in patients treated with pioglitazone or glimepiride. ${ }^{22}$ Criticisms of PERISCOPE were that mild coronary disease only was included in the study, and the clinical relevance of $a<1 \%$ change in atheroma volume was questionable. ${ }^{23}$

\section{GLITAZONES AND HEART FAILURE}

Heart failure, as mentioned above, has been associated with all thiazolidinediones. A recent metaanalysis of seven randomised controlled trials involving 20191 patients found that patients receiving rosiglitazone or pioglitazone had a significantly higher risk of developing heart failure compared with standard treatment or placebo (RR = $1.72,95 \% \mathrm{Cl}=1.21$ to $2.42, P=0.002$ ). Fluid retention, also leading to weight gain, due to direct effects on the kidney has been postulated as a possible mechanism for this effect. ${ }^{24}$

\section{CURRENT GUIDANCE}

In August 2008, the American Food and Drug Administration placed a 'black box' warning on rosiglitazone and pioglitazone labels. They recommended that patients should be monitored for signs of heart failure after initiation of treatment and that glitazones should not be prescribed to patients with New York Heart Association Class III and IV heart failure (moderate to severe symptoms). ${ }^{25}$ They also highlighted the increased risk of myocardial ischaemia associated with rosiglitazone, which was found in some studies, although they suggested overall data were inconclusive. Co-administration of rosiglitazone and insulin was also not recommended. ${ }^{26}$

In October 2007, the European Medicines Agency's Committee for Medicinal Products for Human Use (CHMP) also reviewed the evidence for rosiglitazone and pioglitazone and concluded overall that benefits outweighed risks for both drugs. They did recommend, however, that the product information for rosiglitazone should be updated to reflect concerns regarding risk of myocardial ischaemia in addition to the current warnings carried on both products around heart failure. ${ }^{27}$ In January 2008, following a further meeting of the CHMP, a new warning was added stating that all rosiglitazone products were not recommended in patients with a history of ischaemic heart disease or peripheral vascular disease. They also included a new contraindication stating rosiglitazone should not be used in patients with acute coronary syndrome, including both angina and some types of myocardial infarction. ${ }^{28}$

The National Institute for Health and Clinical Excellence (NICE) published guidance for the management of type 2 diabetes in May 2008. ${ }^{29}$ The guidance does not recommend thiazolidinediones in patients with evidence of heart failure or high risk of fracture, and reiterate the need to monitor for signs of heart failure after starting a thiazolidinedione. Metformin with the addition of a sulphonylurea remains the first-line therapy after a trial of lifestyle interventions; however, if metformin is not tolerated it could be substituted with a glitazone to achieve glycaemic control. Sulphonylureas can be changed to a glitazone if hypoglycaemia is a potential problem. If $\mathrm{HbA} 1 \mathrm{c}$ remains above $7.5 \%$ despite metformin and sulphonylurea, a thiazolidinedione or insulin can be added. A glitazone may be more appropriate if insulin is likely to be unacceptable to the patient or ineffective, for example in obese patients. It is unclear whether glitazones or insulin will be most beneficial in terms of cardiovascular outcomes. NICE has also recommended that pioglitazone may be used in combination with insulin in those patients failing to achieve adequate glycaemic control. They warn particularly in these patients to monitor for signs of fluid retention and discontinue pioglitazone should they occur.

\section{CONCLUSION}

In the past year there have been increasing concerns regarding the cardiovascular safety of thiazolidinediones in type 2 diabetes. Patients with symptomatic heart failure should not receive either rosiglitazone or pioglitazone, and all patients should be monitored for evidence of heart failure while on treatment. Furthermore, rosiglitazone is contraindicated in patients with recent myocardial events and is not recommended in those with an established history of ischaemic heart or peripheral vascular disease. There also remain concerns of increased fracture risk in women receiving rosiglitazone..$^{21}$ These restrictions for rosiglitazone in coronary disease do not extend to pioglitazone, which has increasing evidence for cardioprotection.

Since good glycaemic control remains one of the more difficult therapeutic targets, and management options are limited, the glitazones remain an important class of agents in patients with type 2 diabetes, as long as these new varied precautions and limitations are understood by physicians.

\section{Funding body}

Not applicable 


\section{Competing interests}

FD Richard Hobbs has received occasional sponsorship or fees for speaking and consultancies from GSK and Takeda who both market thiazolidinediones in the UK.

\section{Discuss this article}

Contribute and read comments about this article on the Discussion Forum: http://www.rcgp.org.uk/bjgp-discuss

\section{REFERENCES}

1. Warrell D, Cox TM, Firth J, et al. Oxford textbook of medicine. Oxford: Oxford University Press, 2004

2. International Diabetes Federation. Diabetes atlas. Foreword. http://www.eatlas.idf.org/news.asp?newsid=2007731153431 (accessed 20 Apr 2009).

3. Huxley R, Barzi F, Woodward M. Excess risk of fatal coronary heart disease associated with diabetes in men and women: meta-analysis of 37 prospective cohort studies. BMJ 2006; 332(7533): 73-78.

4. UK Prospective Diabetes Study Group. Intensive blood-glucose control with sulphonylureas or insulin compared with conventional treatment and risk of complications in patients with type 2 diabetes. Lancet 1998; 352: 837-853.

5. Yki-Jarvinen H. Thiazolidinediones. N Engl J Med 2004; 351(11): 1106-1118.

6. Gitlin N, Neil LJ, Spurr CL, et al. Two cases of severe clinical and histologic hepatotoxicity associated with troglitazone. Ann Intern Med 1998; 129(1):36-38.

7. Clifford RJ. The rosiglitazone story — lessons from an FDA advisory committee meeting. N Engl J Med 2007; 357(9): 844-846.

8. The DREAM (Diabetes REduction Assessment with ramipril and rosiglitazone Medication) Trial Investigators. Effect of rosiglitazone on the frequency of diabetes in patients with impaired glucose tolerance or impaired fasting glucose: a randomised controlled trial. Lancet 2006; 368(9541): 1096-1105.

9. Kahn SE, Haffner SM, Heise MA, et al for the ADOPT Study Group. Glycaemic durability of rosiglitazone, metformin or glyburide monotherapy. N Engl J Med 2006; 355(23): 2427-2443.

10. Nissen SE, Wolski K. Effect of rosiglitazone on the risk of myocardial infarction and death from cardiovascular causes. N Engl J Med 2007; 356(24): 1-15.

11. Psaty BM, Furberg CD. Rosiglitazone and cardiovascular risk. N Engl Med 2007; 356(24): 2522-2524.

12. Richter B, Bandeira Echtler E, Bergerhoff K et al. Rosiglitazone for type 2 diabetes mellitus (Review). Cochrane Database Syst Rev 2007; 3: CD006063.

13. Home PD, Pocock SJ, Beck-Nielsen H, et al for the RECORD Study Group. Rosiglitazone Evaluated for Cardiovascular Outcomes - an interim analysis. N Engl J Med 2007; 357(1): 1-11.

14. Dragie HJ, Hildebrandt PR, Riegger GA, et al. A randomised, placebocontrolled trial assessing the effects of rosiglitazone on echocardiographic function and cardiac status in type 2 diabetic patients with New York Heart Association functional class 1 or 2 heart failure. J Am Coll Cardiol 2007; 49(16): 1696-1704.

15. Singh S, Loke YK, Furberg CD. Long-term risk of cardiovascular events with rosiglitazone - a meta-analysis. JAMA 227; 298(10): 1189-1195.
16. Gerrits CM, Bhattacharya M, Manthena S, et al. A comparison of pioglitazone and rosiglitazone for hospitalisation for acute myocardial infarction in type 2 diabetes. Pharmacoepidemiol Drug Saf 2007; 16(10): 1065-1071.

17. Dormandy JA, Charbonnel B, Eckland DJA, et al for the PROactive investigators. Secondary prevention of macrovascular events in patients with type 2 diabetes in the PROactive Study (PROspective pioglitAzone Clinical Trial In macroVascular Events): a randomised controlled trial. Lancet 2005; 366(9493): 1279-1289.

18. Erdmann E, Dormandy JA, Charbonnel B, et al for the PROactive Investigators. The effect of pioglitazone on recurrent myocardial infarction in 2,445 patients with type 2 diabetes and previous myocardial infarction: results from the PROactive (PROactive 05) Study. J Am Coll Cardiol 2007; 49(17): 1772-1780.

19. Wilcox R, Bousser MG, Betteridge J, et al for the PROactive Investigators. Effects of pioglitazone in patients with type 2 diabetes with or without previous stroke. Stroke 2007; 38(3): 865-873.

20. Lincoff AM, Wolski K, Nicholls SJ, et al. Pioglitazone and risk of cardiovascular events in patients with type 2 diabetes mellitus - a meta-analysis of randomized trials. JAMA 2007; 298(10): 1180-1188.

21. Nissen SE, Nicholls SJ, Wolski K, et al for the PERISCOPE Investigators. Comparison of pioglitazone vs glimepiride on progression of coronary atherosclerosis in patients with type 2 diabetes. JAMA 2008; 299(13): 1561-1573.

22. Mazzone T, Meyer PM, Feinstein SB, et al. Effect of pioglitazone compared with glimepiride on carotid intima-media thickness in type 2 diabetes — a randomized trial. JAMA 2006; 296(21): 2572-2581.

23. Steg PG, Marre M. Does PERISCOPE provide a new perspective on diabetic treatment? JAMA 2008; 299(13): 1603-1604.

24. Lago RM, Singh PP, Nesto R. Congestive heart failure and cardiovascular death in patients with prediabetes and type 2 diabetes given thiazolidinediones: a meta-analysis of randomised clinical trials. Lancet 2007; 370(9593): 1129-1136.

25. US Food and Drug Administration Center for Drug Evaluation and Research. Information for healthcare professionals: pioglitazone $\mathrm{HCl}$ (marketed as Actos, Actoplus Met, and Duetact). Rockville: FDA, 2007. http://www.fda.gov/cder/drug/InfoSheets/HCP/pioglitazoneHCP.htm (accessed 20 Apr 2009).

26. US Food and Drug Administration. Highlights of prescribing information: Avandia (rosiglitazone maleate) tablets. Rockville: FDA, 2007. http://www.fda.gov/cder/foi/label/2007/021071s031lbl.pdf (accessed 20 Apr 2009).

27. European Medicines Agency. Press release: European Medicines Agenc confirms positive benefit-risk balance for rosiglitazone and pioglitazone. London: European Medicines Agency, 2007.

http://www.emea.europa.eu/pdfs/human/press/pr/48427707en.pdf (accessed 20 Apr 2009).

28. European Medicines Agency. Press release: EMEA recommends new warnings and contraindications for rosiglitazone. London: European Medicines Agency, 2008.

http://www.emea.europa.eu/humandocs/PDFs/EPAR/avaglim/4223208 en.pdf (accessed 20 Apr 2009).

29. National Institute for Health and Clinical Excellence. Type 2 diabetes: the management of type 2 diabetes (update). Clinical Guideline 66. London: National Institute for Health and Clinical Excellence, 2008. http://www.nice.org.uk/Guidance/CG66 (accessed 20 Apr 2009). 